\title{
Factors driving population recovery of the greater horseshoe bat (Rhinolophus ferrumequinum) in the UK: implications for conservation
}

\author{
Jérémy S. P. Froidevaux ${ }^{1}$ (D) Katherine L. Boughey ${ }^{2}$. \\ Kate E. Barlow ${ }^{2} \cdot$ Gareth Jones $^{1}$
}

Received: 11 May 2016/Revised: 30 January 2017/ Accepted: 10 February 2017/

Published online: 17 February 2017

(C) The Author(s) 2017. This article is published with open access at Springerlink.com

\begin{abstract}
Although populations of many bat species appear to be recovering in some European countries, the extrinsic and intrinsic factors driving these increases have not yet been assessed. Disentangling the benefits of conservation management from other factors such as climate change is a crucial step for improving evidence-based conservation strategies. We used the greater horseshoe bat (Rhinolophus ferrumequinum) as a case study for understanding the recovery of bat populations, as its north-western populations have increased substantially over the past two decades following severe population declines. Using summer roost count data from the UK National Bat Monitoring Programme spanning an 18 year period from 1997 to 2014, we investigated the effects of (i) landscape characteristics associated with the implementation of the agri-environment schemes on colony trends and size, and (ii) meteorological variables on annual colony growth rate. We also assessed the relationship between colony size and colony growth to investigate intrinsic factors such as an Allee effect. Our results indicated that colony size was positively related to a range of landscape features (e.g. amount of broadleaf woodland and grassland, and density of linear features) surrounding the roost, while the amount of artificial light at night had a significant negative effect. Spring temperatures and precipitation (the latter with a lag of one year) were associated with annual colony growth. We also identified a negative density-dependence effect within colonies. Though the conservation of essential landscape elements may have contributed to population increases in the long-term, we conclude that recent population recovery has also been driven by climate
\end{abstract}

Communicated by Dirk Sven Schmeller.

Electronic supplementary material The online version of this article (doi:10.1007/s10531-017-1320-1) contains supplementary material, which is available to authorized users.

Jérémy S. P. Froidevaux

jeremy.froidevaux@bristol.ac.uk

1 School of Biological Sciences, University of Bristol, Life Sciences Building, 24 Tyndall Avenue, Bristol BS8 1TQ, UK

2 Bat Conservation Trust, Quadrant House, 250 Kennington Lane, London SE11 5RD, UK 
change. Finally we recommend that the conservation of photophobic bat species such as $R$. ferrumequinum should focus on both the improvement of foraging/commuting habitats and the creation of dark areas.

Keywords Agri-environment schemes · Climate change · Density-dependence · Landscape characteristics · Light pollution · Population trend

\section{Introduction}

Climate and land-use change are considered to be the main drivers responsible for biodiversity change in terrestrial ecosystems (Pimm and Raven 2000; Walther et al. 2002; Parmesan and Yohe 2003; Foley et al. 2005; Burns et al. 2016; Stephens et al. 2016). While their combined impacts are often overlooked due to their complex interactions (Brook et al. 2008; de Chazal and Rounsevell 2009), there is clear evidence that these two factors have a worldwide influence on the presence, abundance and distribution of a wide range of taxa (Warren et al. 2001; Barbet-Massin et al. 2012). Thus, understanding and disentangling the simultaneous effects of these two driving forces will be a crucial step for developing and evaluating adequate biodiversity conservation strategies, especially as both climate and land-use are changing rapidly (Brook et al. 2008).

Bats can be extremely sensitive to environmental changes (Jones et al. 2009), yet few studies have assessed the relative importance of both climate and land-use for these mammals. Bowler et al. (2015) emphasized the weak influence of climate for explaining local, long-term bat population trends. Similarly, when assessing bat species richness and community composition at a regional scale Mehr et al. (2011) found a much greater effect of land-use compared to climate. However, the assessment of bat activity and species distributions across broader scales, such as across the British range of species has revealed the great importance of meteorological variables in addition to land-use and landscape characteristics (Walsh and Harris 1996; Razgour et al. 2011). These results suggest complex effects of climate and land-use, with bats seeming to respond differently depending on the spatial scale and the type of climatic indicators studied.

The greater horseshoe bat (Rhinolophus ferrumequinum-Schreber 1774) is an excellent model species for investigating temporal population changes in bats in relation to climate and land-use changes. Although this insectivorous species is widely distributed in Europe and considered as Least Concern (LC) on the IUCN Red List, the loss of foraging areas-mainly due to agricultural intensification-and roosts led to a drastic decline in western populations during the twentieth century (Stebbings 1988; Hutson et al. 2001). However, a recent study on its population trends in the United Kingdom (UK) between 1997 and 2012 revealed a significant increase in the overall population size (Barlow et al. 2015), suggesting a population recovery at its northern range margin. The main causes of this increase have yet to be investigated, but two major factors are suspected to be involved. The first one regards changes in farming practices resulting from the implementation of agri-environment schemes (AESs - incentive systems that aim to mitigate the impact of intensive farming on biodiversity). Indeed, land management options targeting $R$. ferrumequinum (e.g. creation and maintenance of permanent cattle-grazed pasture and broad hedgerows) were first integrated into the Countryside Stewardship Scheme administered by the UK government department (Defra, the Department of Environment, Food 
and Rural Affairs) between 1991 and 2004 and then into the Environmental Stewardship schemes. The second factor concerns climate change which may have provided more favourable climatic conditions for this species: for example warmer springs in the UK may have supported population recovery by increasing food availability and shifting the timing of birth to earlier in the year (Ransome and McOwat 1994). Thus, understanding the role of climate and land-use change in a context of population recovery would (i) increase our knowledge on $R$. ferrumequinum population dynamics which will aid in the design of adequate conservation measures and (ii) provide a relatively unique example for other conservationists, as previous studies on land use change have mostly focused on habitat/landscape degradation rather than improvements (Selwood et al. 2015). Furthermore, the potential benefits of AESs on bats have so far been assessed using acoustic indexes (i.e. bat activity) (Fuentes-Montemayor et al. 2011; MacDonald et al. 2012a, b). Because relationships between activity and population size are poorly understood, investigating the relationship between population change over time directly and the implementation of AESs would provide clearer insights into the value of such schemes.

Besides the extrinsic factors outlined above, intrinsic factors may also have led to the population increase. While it has received little attention in studies on bat populations, the demographic Allee effect-defined as a positive relationship between fitness and population size or density (Courchamp et al. 1999; Stephens et al. 1999)—could have a strong influence on population dynamics. The positive relationship may arise from a range of social behaviours (Gregory and Jones 2010). For instance, because females gather in maternity roosts during the summer, mothers and their newborn infants may benefit from social thermoregulation (Willis and Brigham 2007). Moreover, as female relatives forage together (Rossiter et al. 2002), larger colonies may include more matrilineal relatives, facilitating social foraging and/or information transfer. However, although the Allee effect may increase individual fitness while the colony is growing, it may also have a reverse effect when the colony is decreasing, thus accelerating the decline. Therefore, investigating the presence of such an effect is important, especially when studying species of special conservation concern (Gilroy et al. 2012).

In order to fully understand to what extent the effectiveness of species conservation programmes such as AESs could be masked by other factors such as climate change and Allee effect, we investigated which extrinsic and intrinsic factors were the most likely to explain population recovery of $R$. ferrumequinum in the UK. We used count data from maternity colonies of $R$. ferrumequinum inventoried in the UK under the National Bat Monitoring Programme (Walsh et al. 2001; Barlow et al. 2015). Our first objective was to investigate the effects of climate and land-use changes on greater horseshoe bat populations. We tested the hypothesis that targeted AESs would benefit $R$. ferrumequinum populations by examining the effects of landscape characteristics and the amount of land under AESs on two parameters, namely the colony trend (slope of increase) and mean colony size. We then tested the hypothesis that population increase would be related to climate change by examining the relationship between annual colony growth rate and time series meteorological data. Our second objective was to investigate the presence of intrinsic factors that could influence the colony dynamics. We hypothesised that a demographic Allee effect may occur in $R$. ferrumequinum colonies, therefore we tested whether colony size affected annual growth rate. 


\section{Materials and methods}

\section{Greater horseshoe bat monitoring survey}

Maternity colonies of $R$. ferrumequinum have been monitored in the UK by volunteers since 1997 under the National Bat Monitoring Programme (NBMP) (Walsh et al. 2001; Barlow et al. 2015). Roosts of $R$. ferrumequinum were identified by experienced bat workers/volunteers and confirmed using bat detectors [the echolocation calls of this species being easily distinguishable from other bat species in the UK (Parsons and Jones 2000)]. Summer roost counts took place at least twice a year, in the first and second half of July respectively. Individuals were counted during their emergence starting 15 min before sunset. Double-counting was avoided by counting the individuals returning into the roots during dusk emergence. Surveys at a given colony roost were mainly conducted by the same observer throughout the years and only when weather conditions were optimal (i.e. no precipitation, low wind speed and temperatures at sunset $\geq 7{ }^{\circ} \mathrm{C}$ ). Zero counts were reported, thus allowing differentiation of missing values from bat absences. In total, 28 colonies covering the established range of the species in the UK (i.e. south-west England and Wales) were inventoried and monitored between 1997 and 2014 (Fig. 1).

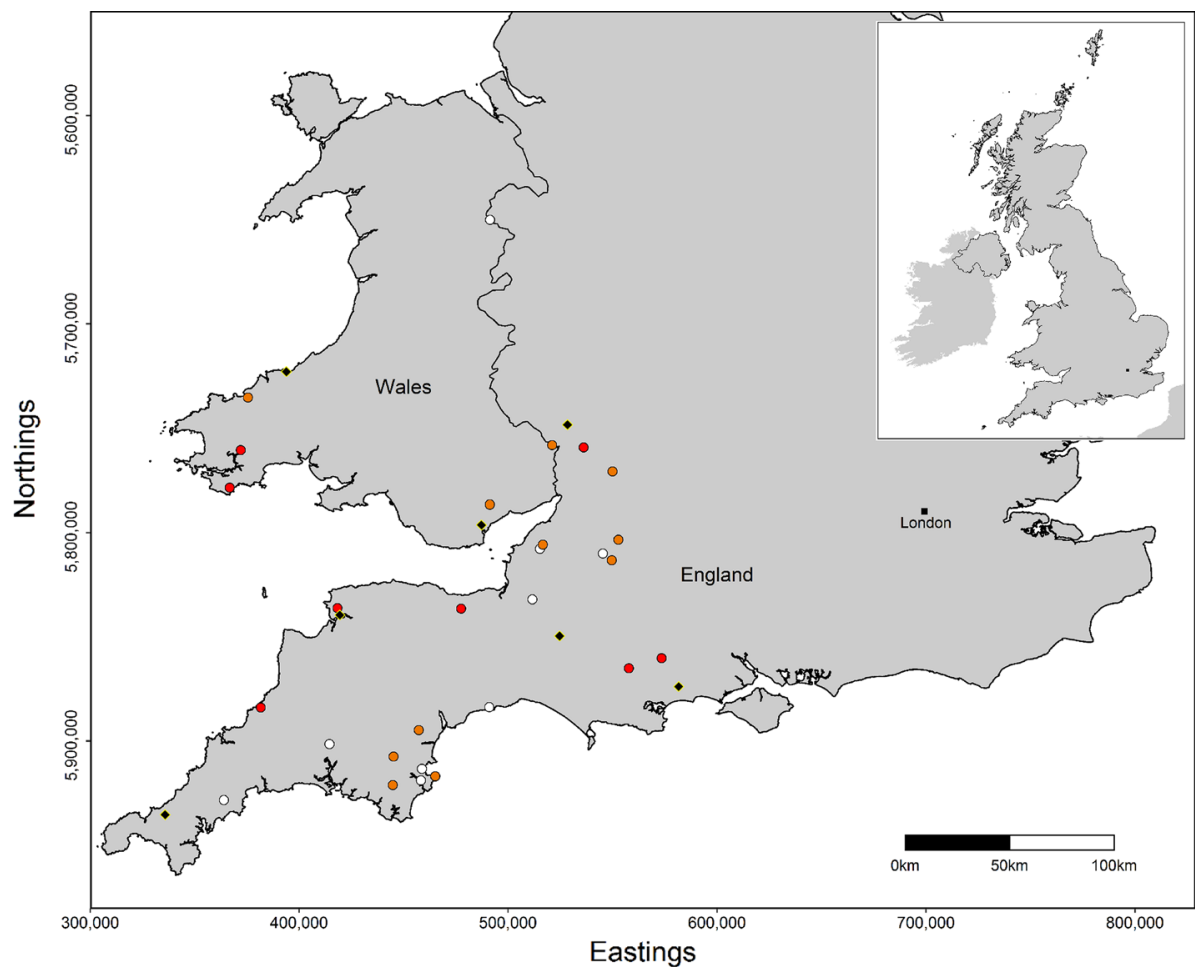

Fig. 1 Location of the seven meteorological stations (black diamonds) matching the distribution of maternity colony roosts (dot symbols) of Rhinolophus ferrumequinum in the United Kingdom. The red dots represent the colony roosts used for the analyses conducted over 18 years, while the colonies used for the analyses conducted over 10 years include sites shown by both red dots and orange dots. (Color figure online) 
From this database, we selected maternity roosts having at least an average of five individuals throughout the years surveyed. By doing so, roosts rarely and sporadically occupied by $R$. ferrumequinum were not incorporated into the analyses. Furthermore, although late July generally represents the period of which juveniles become able to fly (Jones et al. 1995), this period may be advanced or delayed due to spring meteorological conditions affecting birth timing (Ransome and McOwat 1994). As this year-dependent effect may bias the colony size comparisons across years, only data arising from the early July surveys were considered for further analyses as it is highly unlikely that juveniles are flying then.

\section{Measurements of colony trend, mean colony size and annual growth rate}

We used the program Trends and Indices for Monitoring data (TRIM v3.53) to model and test the long-term trends in colony size (Pannekoek and Van Strien 2001). The trend measured in this study corresponds to the slope of the trend line of estimated colony size (hereafter referred to as 'colony trend'). TRIM implements a log-linear Poisson regression to analyse time series of count data and corrects for possible over-dispersion of the data and serial correlation. Because few colonies had been surveyed over the period 1997-2004, we built two separate models by distinguishing colonies having records from 1997 to 2014 (i.e. 18 years, 8 colonies) from those surveyed between 2005 and 2014 (i.e. 10 years, 19 colonies). Finally, though we were aware that conducting trend analyses on a single colony may lead to an overfitting of the model and consequently to an underestimation of the standard errors, trends of each maternity colony were calculated separately in order to examine variation among colonies and investigate factors influencing this variation.

Mean colony size was calculated only over the period 2005-2014, when most of the species monitoring data were collected. For each colony, we averaged the colony size values recorded during this time period to avoid serial correlation when analysing the data. One colony was excluded from analysis because we identified it as an influential outlier.

We investigated the annual fluctuations in colony size by calculating the annual growth rate $\left(r_{t}\right)$ for each colony:

$$
r_{t}=\left(N_{t}-N_{t-1}\right) /\left(N_{t-1}\right) * 100
$$

where $N$ is the number of individuals of a given colony at years $t$ or $t-1$.

\section{Environmental and meteorological variables}

\section{Landscape characteristics and land-use data}

We created three buffers $(0.5,1.5$ and $3.0 \mathrm{~km}$ radii) around the maternity roosts using ArcGIS Desktop v10 (ESRI, Redlands, CA) to represent the most relevant spatial scales when studying $R$. ferrumequinum. While the small scale $(0.5 \mathrm{~km})$ allow us to describe the near environment of the roost location, the core sustenance zone of juveniles and adults $R$. ferrumequinum are represented with the medium $(1.5 \mathrm{~km})$ and large scales $(3.0 \mathrm{~km})$ respectively (Duvergé and Jones 1994; Rossiter et al. 2002; Flanders and Jones 2009; Dietz et al. 2013; Collins 2016). The core sustenance zones for bats is expressed for a given species as its main foraging area surrounding the roost based on its average-maximum foraging radius. 
Within each buffer, we extracted data from (i) the Land Cover Map 2007 (LCM2007) supplied by the Centre of Ecology and Hydrology (CEH; Morton et al. 2011) and (ii) the AESs established in England spanning the period 2006-2014 which were provided by Natural England (www.gov.uk/government/organisations/natural-england). The 23 LCM2007 classes representing the UK broad habitats were reclassified in nine aggregate land classes: broadleaf woodland, coniferous woodland, arable land, grassland, saltwater, freshwater, coastal land, urban area (excluding small roads) and other (Online Resource 1). Changes of land-cover that have occurred within the buffer of $3.0 \mathrm{~km}$ radius around the maternity colony roosts between 2000 and 2012 were small enough to consider the LCM2007 representative for the time scale studied (only $0.40 \%$ of the land-cover have been modified; Online Resource 2). The AESs were redefined according to their specific tier: (i) Entry Level Stewardship (ELS) and (ii) the more targeted Higher Level Stewardship (HLS). Moreover, we distinguished HLS options focussing specifically on habitats preferred by $R$. ferrumequinum (i.e. management of hedgerows, maintenance and restoration of wood pasture/woodland/grassland; Online Resource 3) from the other options.

Using the reclassified LCM2007, we calculated the proportion of each land class at each of the three spatial scales. We then conducted a landscape analysis with Fragstats 4.2 (McGarigal et al. 2002) using the nine land classes to describe the fragmentation, heterogeneity, and diversity of the landscapes at the largest scale by using the mean patch area, the patch richness density, and the Shannon's diversity index respectively (Table 1). Similarly, we calculated the percentage of total area under (i) AESs independently of the tier; (ii) ELS; (iii) HLS regardless of the options implemented; and (iv) relevant HLS options targeting the conservation of $R$. ferrumequinum. Furthermore, since linear features (hedgerows and tree lines) constitute part of the main foraging and commuting habitats of $R$. ferrumequinum (Duvergé and Jones 1994; Dietz et al. 2013), the density of these linear features was evaluated for each landscape. Hedgerows and tree lines were digitized using Google Earth aerial photographs taken between 2010 and 2014. Finally, to consider the potential negative effect of light pollution on horseshoe bats (Stone et al. 2009), we also extracted the map of artificial light at night (ALAN) derived from a cloud-free composite of VIIRS night-time lights (July 2014; 15 arc-seconds resolution) and produced by the Earth Observation Group, NOAA National Geophysical Data Centre (http://www.ngdc. noaa.gov/eog/viirs/download_monthly.html). We subsequently quantified the average level of light pollution at the three spatial scales (Table 1).

\section{Meteorological data}

Time series of minimum temperatures and precipitation data spanning 1997-2014 were obtained at monthly resolution from seven meteorological stations (www.metoffice.gov. uk) matching the distribution range of $R$. ferrumequinum within the UK (Table 1; Fig. 1). Although some maternity roosts were distant from the meteorological stations (mean geodesic distance: $44 \mathrm{~km}$, ranging from 3 to $95 \mathrm{~km}$ ), we did not intend to compare climatic values among sites but rather across years. Hence the data extracted here represent the broad-scale climatic conditions where the species occurs in the UK. North Atlantic Oscillation (NAO) indices-defined as the normalized pressure difference between Gibraltar and Reykjavik (Jones et al. 1997)—were extracted with monthly resolution from the Climatic Research Unit, University of East Anglia, Norwich (www.cru.uea.ac.uk/ $\sim$ timo/datapages/naoi.htm). NAO indices may be interpreted as a broad-scale climate indicator. 
Table 1 Variables used to assess the effects of climate, landscape characteristics and AESs on Rhinolophus ferrumequinum maternity colonies

\begin{tabular}{|c|c|c|c|}
\hline Category & Variable & Description & Unit \\
\hline \multirow[t]{3}{*}{$\begin{array}{l}\text { Meteorological } \\
\text { data }\end{array}$} & $\begin{array}{l}\text { Time series } \\
\text { temperature data }\end{array}$ & $\begin{array}{l}\text { Minimum temperatures recorded for the period } \\
\text { 1997-2014 }\end{array}$ & ${ }^{\circ} \mathrm{C}$ \\
\hline & $\begin{array}{l}\text { Time series } \\
\text { precipitation data }\end{array}$ & $\begin{array}{l}\text { Amount of precipitations recorded for the period } \\
1997-2014\end{array}$ & $\mathrm{~mm}$ \\
\hline & $\begin{array}{l}\text { Time series NAO } \\
\text { indices }\end{array}$ & $\begin{array}{l}\text { North Atlantic Oscillation indices calculated for the } \\
\text { period 1997-2014 }\end{array}$ & index \\
\hline \multirow[t]{6}{*}{$\begin{array}{l}\text { Landscape } \\
\text { characteristics }\end{array}$} & $\begin{array}{l}\text { Landscape } \\
\text { fragmentation }^{\mathrm{a}}\end{array}$ & $\begin{array}{l}\text { Mean area of the habitat patches within the } \\
\text { landscape }\end{array}$ & ha \\
\hline & $\begin{array}{l}\text { Landscape } \\
\text { heterogeneity }^{\mathrm{a}}\end{array}$ & Patch richness density within the landscape & no/100 ha \\
\hline & Landscape diversity ${ }^{\mathrm{a}}$ & $\begin{array}{l}\text { Shannon's diversity index: diversity of habitats } \\
\text { within the landscape }\end{array}$ & index \\
\hline & $\begin{array}{l}\text { Density of linear } \\
\text { features }\end{array}$ & $\begin{array}{l}\text { Density of hedgerows and tree lines within the } \\
\text { landscape }\end{array}$ & $\mathrm{m} / \mathrm{ha}$ \\
\hline & $\begin{array}{l}\text { Amount of artificial } \\
\text { light at night } \\
(\text { ALAN })^{\mathrm{b}}\end{array}$ & Level of artificial light at night within the landscape & $\begin{array}{c}\text { nanowatts/ } \\
\mathrm{cm}^{2} / \mathrm{sr}\end{array}$ \\
\hline & $\begin{array}{l}\text { Proportion of each } \\
\text { land class }\end{array}$ & $\begin{array}{l}\text { Proportion of a given land class within the } \\
\text { landscape }\end{array}$ & $\%$ \\
\hline \multirow[t]{4}{*}{ AESs } & $\begin{array}{l}\text { AESs-all options } \\
\text { included }^{\text {b }}\end{array}$ & $\begin{array}{l}\text { Proportion of areas under ELS and/or HLS } \\
\text { management within the landscape }\end{array}$ & $\%$ \\
\hline & $\mathrm{ELS}^{\mathrm{b}}$ & $\begin{array}{l}\text { Proportion of areas under ELS management within } \\
\text { the landscape }\end{array}$ & $\%$ \\
\hline & $\mathrm{HLS}^{\mathrm{b}}$ & $\begin{array}{l}\text { Proportion of areas under HLS management within } \\
\text { the landscape }\end{array}$ & $\%$ \\
\hline & $\begin{array}{l}\text { HLS-R. } \\
\text { ferrumequinum }^{\mathrm{b}}\end{array}$ & $\begin{array}{l}\text { Proportion of areas under HLS management within } \\
\text { the landscape with options of potential benefit to } \\
\text { the conservation of } R \text {. ferrumequinum }\end{array}$ & $\%$ \\
\hline
\end{tabular}

a Variables taken within a buffer of $3.0 \mathrm{~km}$ radius around the maternity colony roosts considering all land classes

b Variables taken within a buffer of $0.5,1.5$ and $3.0 \mathrm{~km}$ radius around the maternity colony roosts AESs: agri-environment schemes; ELS: entry level stewardship; HLS: high level stewardship

\section{Statistical analyses}

All the analyses were performed using the R statistical software ( $\mathrm{R}$ Development Core Team 2015).

\section{Extrinsic factors}

At each spatial scale we evaluated the effects of landscape characteristics and AESs on (i) colony trends by fitting multiple linear regression models using the log-transformed data to respect normality assumptions and (ii) mean colony sizes of $R$. ferrumequinum using generalized linear models with a negative binomial distribution for handling overdispersion in the data ("MASS" package). The independent variables were standardized beforehand to obtain the same unit measures and tested for correlations with the Spearman's correlation test. When highly correlated variables were found $(|r| \geq 0.7$; Online 
Resource 4), we retained the variable having the highest perceived ecological importance (based on published literature, e.g. Duvergé and Jones 1994, 2003; Flanders and Jones 2009; Dietz et al. 2013). When we found strong correlations between two variables having similar importance (e.g. the amount of ALAN and proportion of urban area) we assessed independently each variable in our models and retained the variable having the most explanatory power (i.e. the largest effect size; Online Resource 5). We tested the spatial correlation of both mean colony size and colony trend by performing the Mantel test; no spatial correlation was found (Online Resource 6). Finally, we applied an informationtheoretic approach to select the most parsimonious models, using the second order information criterion $(A I C C)$ in the model selection process (Burnham and Anderson 2002). In order to obtain robust estimates and corresponding standard errors when equivalent best models were found $(\triangle A I C c<2)$, we undertook model averaging over all models within $\triangle A I C c<2$. Following the recommendations of Arnold (2010), the significance of the effect of each variable present within the best models was assessed through $85 \%$ confidence intervals $(\mathrm{CI})$ of their relative estimate, considering the effect as statistically significant when CI did not overlap zero.

Temporal synchronies between annual colony growth rate and time series of meteorological variables for the two periods 1997-2014 and 2005-2014 were assessed using crosscorrelation functions (CCF). We tested the significance of the correlation coefficients with the Bartlett's band $\pm 2 / \sqrt{ } n$ ( $n$ being the time series' length). Because we expected climatic variables to influence the annual colony growth rate either immediately or with a time lag of a few years, only correlation coefficients within a maximum of three years lag were taken into account. Thus, we compared the growth rate values calculated between years $t_{i}$ and $t_{i}-1$ to the meteorological variable values of years $t_{i}, t_{i}-1, t_{i}-2$ and $t_{i}-3$. Serial correlation and its relative significance was tested with the autocorrelation function (ACF) and Bartlett's band $\pm 2 / \sqrt{ } n$ respectively, whereas spatial autocorrelation was assessed using the Mantel test. No evidence of temporal or spatial correlation was found (Online Resource 6).

\section{Intrinsic factors}

Given that the dynamics of $R$. ferrumequinum colonies may exhibit either a negative densitydependence or a demographic Allee effect (Courchamp et al. 1999; Gregory and Jones 2010), we assessed the existence of these relationships using the annual colony growth rate as a surrogate of individual fitness. We used data arising from colonies surveyed for at least two consecutive years during the period 1997-2014 (22 colonies). The influence of colony size on the growth rate was fitted using generalized linear mixed models with a negative binomial distribution to account for overdispersion. Growth rate $\left(r_{t}\right)$ was transformed beforehand into a growth factor $g\left(\right.$ with $\left.g=\left(r_{t} / 100\right)+1\right)$ in order to fit the negative binomial distribution. The linear, as well as the quadratic term of colony size, were included in the models for testing density-dependence and the Allee effect respectively (Sæther et al. 1996; Angulo et al. 2007). The year and colony identity were included as random factors to control for pseudo-replication. We applied the same model selection approach as previously described.

\section{Results}

Overall, maternity colonies of $R$. ferrumequinum showed a significant increase in size (Fig. 2) regardless of the period surveyed (1997-2014: annual growth rate of $5.40 \pm 0.47 \%$, lower $95 \% \mathrm{CI}=4.44 \%$, upper $95 \% \mathrm{CI}=6.36 \% ; 2005-2014$ : annual 
growth rate of $4.38 \pm 0.66 \%$, lower $95 \% \mathrm{CI}=3.09 \%$, upper $95 \% \mathrm{CI}=5.67 \%$ ). Of the eight colonies monitored between 1997 and 2014, seven increased and one exhibited a stable trend. Similarly, most colonies increased for the 2005-2014 period, with positive trends observed in 14 colonies, stable trends in four, and a negative trend detected in only one (Online Resource 7).

\section{Landscape characteristics and AESs}

When testing the relationship between colony trend and landscape characteristics and AESs, none of the explanatory variables were included in the most parsimonious model. However, when looking at colony size, the best generalized linear models (Table 2) indicated that variations in mean colony size were significantly explained by the landscape characteristics surrounding the roosts (Table 3). No variable reflecting the implementation of AESs appeared in the most parsimonious models. We also found that the significance of landscape variables was scale-dependent. At the smallest scale $(0.5 \mathrm{~km})$, the best models included the amount of artificial light at night (ALAN), the density of linear features, and the proportion of broadleaf woodland and urban area. Amongst these variables, only the amount of ALAN did not have evidence to support its importance since the $85 \% \mathrm{CI}$ overlapped zero. At the medium scale $(1.5 \mathrm{~km})$, the amount of ALAN, as well as the proportion of broadleaf woodland and grassland, were retained in the best models. Finally at largest scale $(3.0 \mathrm{~km})$, the most parsimonious models incorporated the amount of ALAN, the density of linear features and the proportion of grassland. The direction of the effects were identical regardless of the spatial scales studied: while the amount of ALAN and the proportion of urban areas were negatively related to colony size, we found a positive effect of the density of linear features and the proportion of woodland and grassland (Fig. 3).
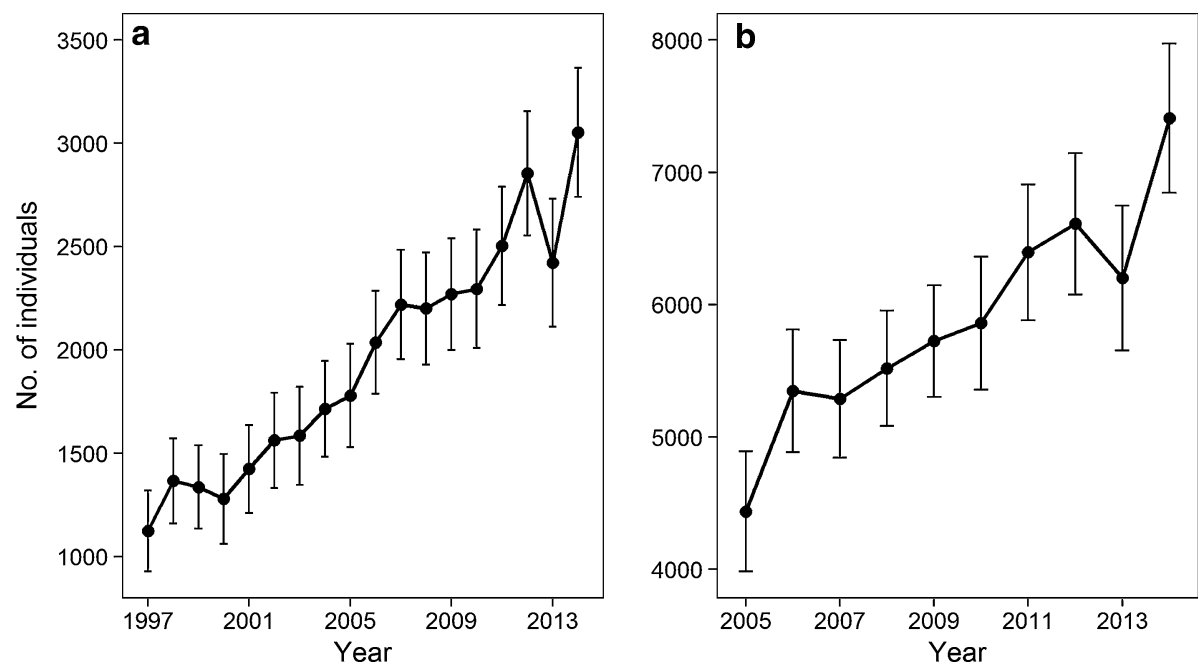

Fig. 2 Colony trends of Rhinolophus ferrumequinum based on count data arising from a 8 colonies over the period 1997-2014 (18 years) and b 19 colonies spanning the period 2005-2014 (10 years). Total annual count and associated $95 \%$ confidence intervals are indicated in black 
Table 2 Results of the stepwise selection of GLMs (Negative Binomial Family) built to assess the relationships between colony sizes of $R$. ferrumequinum and landscape features and agri-environment schemes

\begin{tabular}{|c|c|c|c|c|c|c|c|}
\hline Scale & Model & $K$ & $A I C c$ & $\triangle A I C c$ & $\begin{array}{l}A I C c \\
W t\end{array}$ & $\begin{array}{l}\text { Cum. } \\
W t\end{array}$ & $\begin{array}{l}\text { pseudo } \\
R^{2 a}\end{array}$ \\
\hline \multirow{5}{*}{$\begin{array}{c}0.5 \mathrm{~km} \\
\text { radius } \\
\text { zone }^{b}\end{array}$} & $\%$ of urban area & 3 & 226.40 & 0.00 & 0.43 & 0.43 & 0.33 \\
\hline & $\begin{array}{l}\% \text { of urban area }+\% \text { of broadleaf } \\
\text { woodland }+ \text { Density of linear features }\end{array}$ & 5 & 226.54 & 0.14 & 0.41 & 0.84 & 0.54 \\
\hline & $\%$ of urban area + Amount of ALAN & 4 & 228.39 & 1.99 & 0.16 & 1.00 & 0.38 \\
\hline & $\begin{array}{l}\% \text { of urban area }+\% \text { of broadleaf } \\
\text { woodland }\end{array}$ & 4 & 228.51 & 2.11 & - & - & 0.37 \\
\hline & $\begin{array}{l}\% \text { of urban area }+ \text { Density of linear } \\
\text { features }\end{array}$ & 4 & 228.69 & 2.29 & - & - & 0.36 \\
\hline \multirow{5}{*}{$\begin{array}{c}1.5 \mathrm{~km} \\
\text { radius } \\
\text { zone }^{\mathrm{c}}\end{array}$} & $\%$ of grassland + Amount of ALAN & 4 & 227.58 & 0.00 & 0.29 & 0.29 & 0.40 \\
\hline & $\begin{array}{l}\% \text { of grassland }+\% \text { of broadleaf } \\
\text { woodland }\end{array}$ & 4 & 227.65 & 0.07 & 0.28 & 0.57 & 0.40 \\
\hline & $\%$ of grassland & 3 & 227.75 & 0.17 & 0.27 & 0.84 & 0.28 \\
\hline & Amount of ALAN & 3 & 228.84 & 1.26 & 0.16 & 1.00 & 0.23 \\
\hline & $\begin{array}{l}\% \text { of grassland }+ \text { Amount of ALAN }+\% \\
\text { of broadleaf woodland }\end{array}$ & 5 & 229.70 & 2.12 & - & - & 0.46 \\
\hline \multirow{5}{*}{$\begin{array}{c}3.0 \mathrm{~km} \\
\text { radius } \\
\text { zone }^{\mathrm{d}}\end{array}$} & Amount of ALAN & 3 & 227.60 & 0.00 & 0.36 & 0.36 & 0.28 \\
\hline & $\%$ of grassland & 3 & 227.99 & 0.39 & 0.29 & 0.65 & 0.27 \\
\hline & Amount of ALAN $+\%$ of grassland & 4 & 228.67 & 1.07 & 0.21 & 0.86 & 0.36 \\
\hline & Density of linear features & 3 & 229.47 & 1.87 & 0.14 & 1.00 & 0.21 \\
\hline & $\begin{array}{l}\text { Amount of ALAN + Density of linear } \\
\text { features }\end{array}$ & 4 & 229.81 & 2.21 & - & - & 0.32 \\
\hline
\end{tabular}

Model selection process was based on the second order information criterion (AICC). Models are ranked by $A I C c$ values; only the top five models are shown. The number of parameters $(K)$, the $A I C c$ and pseudo $R^{2}$ are given for each model. AICc weight (Wt) and cumulative weight (Cum. Wt) are given for the most parsimonious models only $(\triangle A I C c<2)$

${ }^{\text {a }}$ Pseudo $R^{2}=1-$ (residual deviance/null deviance) (Faraway 2006)

b Near environment of the roost location

c Core sustenance zone of juveniles

d Core sustenance zone of adults

$A L A N$ artificial light at night

\section{Climate}

Annual colony growth rate was significantly synchronised with a set of meteorological variables. For the 2005-2014 period ( $\mathrm{N}=19$ colonies), spring precipitation was negatively correlated with growth rate $(r=-0.85)$ with a lag effect of one year (Fig. 4a). There was clear evidence for a positive influence of minimum spring temperature on growth rate $(r=0.84$; Fig. $4 \mathrm{~b})$, without any lag effect. When investigating temporal synchronies across a longer period (1997-2014, $\mathrm{N}=8$ colonies), spring precipitation displayed a strong significant negative correlation $(r=-0.71)$, again with a lag effect of one year. Minimum spring temperature was positively and significantly associated with growth rate $(r=0.52)$. 
Table 3 Standardized, model-averaged parameter estimates with associated standards errors (SE) and lower and upper $85 \%$ confidence intervals $(\mathrm{CI})$ of the best GLMs $(\triangle A I C c<2)$ explaining colony sizes of Rhinolophus ferrumequinum at three spatial scales

\begin{tabular}{|c|c|c|c|c|c|}
\hline Scale & Variable & Estimate & SE & Lower $85 \%$ CI & Upper $85 \% \mathrm{CI}$ \\
\hline \multirow[t]{4}{*}{$0.5 \mathrm{~km}$ radius zone $\mathrm{a}^{\mathrm{a}}$} & Amount of ALAN & -0.15 & 0.14 & -0.34 & 0.04 \\
\hline & Density of linear features & 0.32 & 0.15 & 0.11 & 0.52 \\
\hline & $\%$ of broadleaf woodland & 0.30 & 0.14 & 0.10 & 0.50 \\
\hline & $\%$ of urban area & -0.41 & 0.13 & -0.59 & -0.23 \\
\hline \multirow[t]{3}{*}{$1.5 \mathrm{~km}$ radius zone ${ }^{\mathrm{b}}$} & Amount of ALAN & -0.28 & 0.15 & -0.48 & -0.07 \\
\hline & $\%$ of broadleaf woodland & 0.20 & 0.13 & 0.02 & 0.38 \\
\hline & $\%$ of grassland & 0.38 & 0.14 & 0.17 & 0.58 \\
\hline \multirow[t]{3}{*}{$3.0 \mathrm{~km}$ radius zone ${ }^{\mathrm{c}}$} & Amount of ALAN & -0.34 & 0.16 & -0.56 & -0.12 \\
\hline & Density of linear features & 0.31 & 0.14 & 0.11 & 0.51 \\
\hline & $\%$ of grassland & 0.31 & 0.16 & 0.09 & 0.53 \\
\hline
\end{tabular}

\footnotetext{
${ }^{a}$ Near environment of the roost location

b Core sustenance zone of juveniles

c Core sustenance zone of adults

$A L A N$ artificial light at night
}
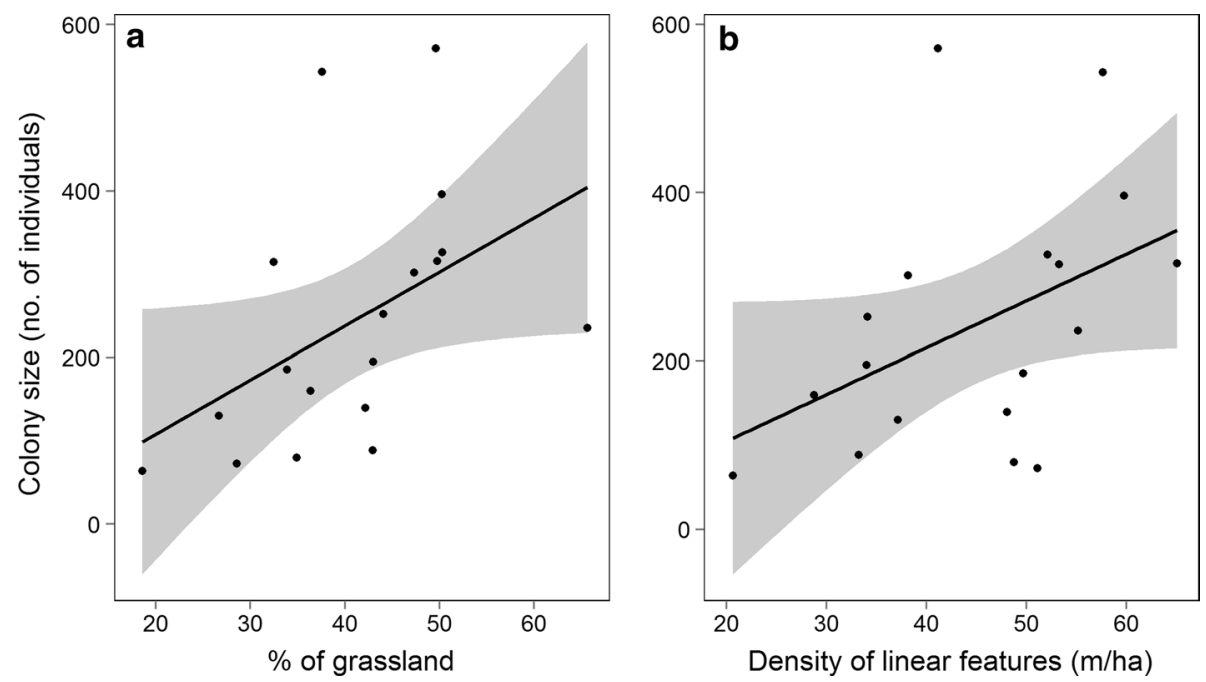

Fig. 3 Positive linear relationships between mean colony size of $R$. ferrumequinum (period 2005-2014) and a proportion of grassland $(\%)$ within the landscape surrounding the roosts at the medium scale (core sustenance zone of juveniles); $\mathbf{b}$ density of linear features $(\mathrm{m} / \mathrm{ha})$ within the landscape surrounding the roosts at the largest scale (core sustenance zone of adults). The regression line is indicated in black with its $95 \%$ confidence interval in grey

\section{Colony size}

When analysing the influence of colony size on annual growth rate, the most parsimonious model included only the linear effect of the colony size. A significant negative density- 
dependence was found (estimate $=-0.04 \pm 0.01$, lower $85 \% \mathrm{CI}=-0.05$, upper $85 \%$ $\mathrm{CI}=-0.03$ ), suggesting that the largest maternity colonies had a lower annual growth rate than small colonies (Fig. 5). Larger colonies had less variation in growth rate, with a relatively constant annual growth rate observed close to zero.

\section{Discussion}

As previously demonstrated by Barlow et al. (2015), bat populations of many species seem to be recovering in the Great Britain as well as in other European countries (Van der Meij et al. 2015). Using a bat species of special conservation concern - the greater horseshoe bat (Rhinolophus ferrumequinum) — as a case study for investigating the effects of climate, landscape characteristics and AESs on changes in maternity colony size, our results provide ample evidence of the complex effects of both landscape characteristics and climate on bat populations, but at different extents. While we expected to find a positive association between the amount of surrounding land under AESs with colony trend and size, our results suggest no clear evidence of these relationships. However, colony size was associated with landscape features that are a common target of AES prescriptions (e.g. broadleaf woodland, grassland and linear features such as hedgerows). Regarding our
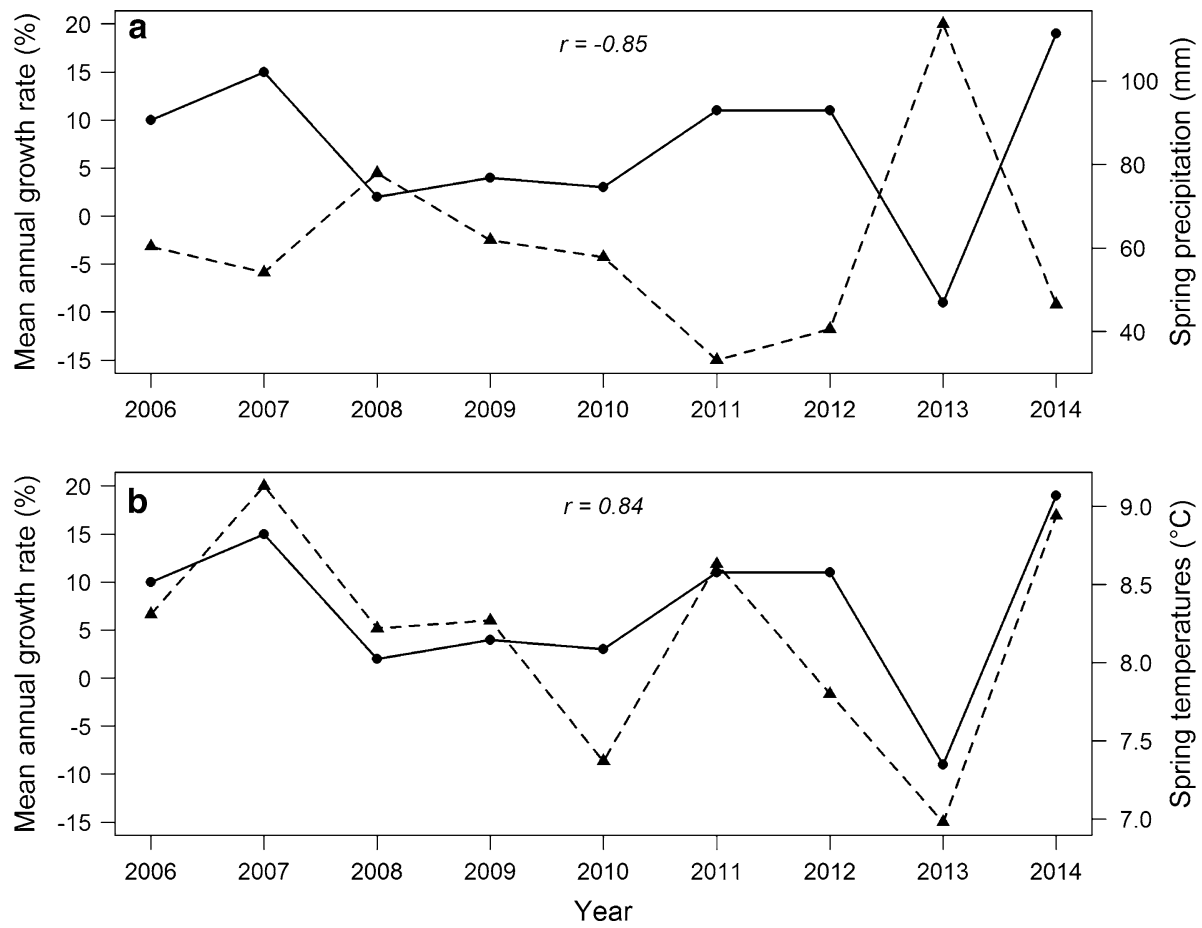

Fig. 4 Temporal synchronies between the mean annual growth rate of 19 Rhinolophus ferrumequinum colonies (black solid line) and a the spring precipitation delayed by one year and $\mathbf{b}$ the minimum spring temperatures (black dotted lines; mean values of April, May and June). $r$ represents the correlation coefficient arising from the cross-correlation functions for the period 2005-2014. Values with a lag effect (i.e. spring precipitation) were adjusted accordingly for a better visual comparison 


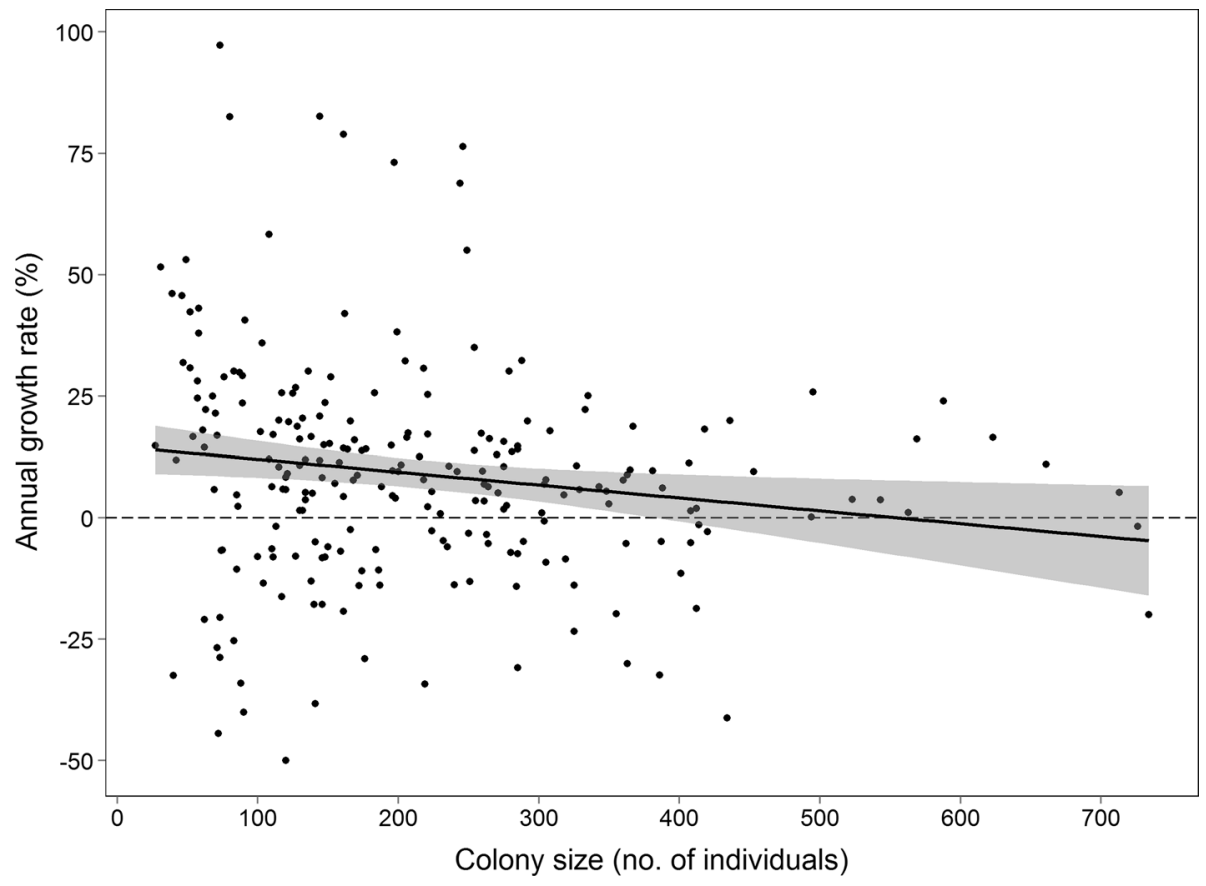

Fig. 5 Negative linear relationship between the annual growth rate between year $t$ and $t-1$ of 22 Rhinolophus ferrumequinum colonies and their respective size at year $t-1$ over the period 1997-2014 (18 years). The black solid line represents the significant density-dependence with its $95 \%$ confidence interval in grey. The black dashed line corresponds to the null growth rate

second hypothesis, we found that the annual growth rate of colonies was strongly correlated with spring temperatures and precipitation. Given that spring temperatures, unlike precipitation, have substantially increased in the past decades in the UK (Online Resource 8 ), the increase in $R$. ferrumequinum populations observed may be attributed at least in part to climate change. Our results also indicate the influence of intrinsic factors on colony growth rate, as we detected negative density-dependence rather than a demographic Allee effect within the colonies.

By using the summer roost count data of maternity colonies as a proxy for identifying patterns of change in $R$. ferrumequinum populations, we were aware that some limitations in the data could have biased our interpretations. For example, information on each individual (e.g. age class, sex, etc.) was not available by employing this non-invasive method. Thus, while we could distinguish subadult and adult bats from juveniles by considering only count data undertaken in early July (i.e. when juveniles are unable to fly), we had to assume that sex ratio of subadult and adult female bats to males was high and constant over the period surveyed and that no immigration or emigration occurred between years. Although we acknowledge that variations in these parameters may bias our findings to some extent, the literature provides strong support towards our assumptions. Ransome (2008) and Schaub et al. (2007) emphasized the fact that $R$. ferrumequinum males, unlike females, present weak philopatry to their summer roost. Though young males may return to the roost after their first year, this philopatric behaviour tends to disappear in subsequent years. Ransome (2008) also highlighted that immigrant females are occasionally present 
within colonies but are rarely present during the breeding season. Thus, we assume that changes in sex ratio and immigration/emigration played only a small role in affecting changes in colony size.

\section{Landscape characteristics affect colony size at different spatial scales}

Amongst the landscape elements investigated, the density of linear features and the proportion of broadleaf woodland and grassland in the landscape surrounding the roost were positively related to colony size. As emphasized by other studies (e.g. Dietz et al. 2013), landscapes supporting highly connected and structured semi-open habitats (i.e. a mixture of grassland and broadleaf woodland connected with hedgerows and tree lines) are the most favourable for $R$. ferrumequinum. Given that pastures and broadleaved woodland are the major foraging habitats for juveniles and adults (Duvergé and Jones 1994, 2003), these results indicate that the availability of foraging areas surrounding the colony roosts may influence the carrying capacity of the colonies within the landscape (Russo et al. 2010; Dietz et al. 2013). As observed in other bat species, intraspecific competition for food may (i) increase flight distances to reach available foraging areas and (ii) reduce prey capture rates, both of which may reduce individual fitness. We further found light pollution to be negatively related to colony size. $R$. ferrumequinum is regarded as a photophobic species and therefore avoids lighted areas whilst foraging or commuting (Stone et al. 2009). Interestingly, the size of colonies was better predicted by the amount of artificial light at night (ALAN) than the proportion of urban area. This finding may arise from the fact that ALAN within landscapes is not systematically restricted to urban areas and may affect the adjacent habitats, thus reducing the foraging areas available for bats (Threlfall et al. 2013; Azam et al. 2016). Furthermore, ALAN — which could also be related to road densitymay act as a barrier to movement by altering gap crossing behaviour (Hale et al. 2015).

While the medium and large spatial scales considered by this study $(1.5$ and $3 \mathrm{~km})$ relate to the core sustenance zone required by $R$. ferrumequinum, the smallest scale considered $(0.5 \mathrm{~km})$ can be interpreted with regard to the roost location itself. At this scale our results highlight a marked positive effect of the proportion of broadleaf woodland in addition to the density of linear features on colony size. These findings corroborate several studies that show that roost locations of bats across the UK are positively associated with broadleaf woodland (Boughey et al. 2011a; Bellamy and Altringham 2015) and that bats use hedgerows and tree lines as landmarks for commuting towards foraging areas when leaving the roost (Limpens and Kapteyn 1991). As well as these positive relationships, our results indicate a negative effect of the proportion of urban area. Although in Great Britain $R$. ferrumequinum mainly uses large old buildings for roosting, the location of the roost itself must be away from urban areas to support a greater number of individuals (Ransome 2008). Finally, as lighting near colony roosts is known to have detrimental effects on photophobic bat species (Boldogh et al. 2007), our results regarding the non-significant effect of ALAN on $R$. ferrumequinum at the smallest spatial scale $(0.5 \mathrm{~km})$ should be interpreted with caution. The lack of effect found in our study may arise from the low resolution of the ALAN data at this scale.

The implementation of AESs on land surrounding the colony roosts has been suggested as one of the most plausible reasons for increasing $R$. ferrumequinum colony sizes (Longley 2003), yet we found no relationship between amount of land under AES and colony size at the spatial scales and time period studied here. The ineffectiveness of AESs for enhancing bat populations in farmland-dominated landscapes has also been reported elsewhere in the UK (Fuentes-Montemayor et al. 2011; MacDonald et al. 2012a, b). These 
studies demonstrated that regardless of the species, the level of bat activity is not significantly different between matched conventional and AES fields. Rather, the amount of particular habitat types within the surrounding landscape seems to be more important for bats (Fuentes-Montemayor et al. 2011; Treitler et al. 2016). Nevertheless, we acknowledge that some limitations in our analysis may have led to this result. The dataset of AESs we used arise from the period 2006-2014 (i.e. AESs implemented after the Common Agricultural Policy reform of 2005), yet most of the prescriptions favourable to R. ferrumequinum were implemented prior to this, between 1998 and 2003 (Longley 2003), as part of the preceding Countryside Stewardship Scheme (CSS). The apparent lack of effect of AESs found in our study could also be explained by landscape-moderated effects (Batáry et al. 2010; Concepción et al. 2012; Tscharntke et al. 2012). Indeed, because we found that $R$. ferrumequinum colony size was positively associated with landscape features commonly targeted by AES prescriptions, such as broadleaf woodland, pasture and hedgerows, it is likely that the landscapes sampled here have been protected by AESs (and CSS) that were initiated before the AES data used in this study were collected. In this case, the high degree of complexity/connectivity of the landscapes may have reduced the effectiveness of AESs implemented after 2005 (Batáry et al. 2010; Concepción et al. 2012; Tscharntke et al. 2012).

\section{Temporal synchronies between meteorological data and growth rate}

When relating annual colony growth rate with time series meteorological data, we found that higher spring temperatures were associated with a higher growth rate. This finding is consistent with the study of Ransome and McOwat (1994) who demonstrate that population recovery of $R$. ferrumequinum occurs after favourable spring weather conditions. Given that we used data from the period before which juveniles are able to fly, the main driver of colony growth as measured by this study is overwinter survival, particularly of juveniles. Early spring corresponds to the most vulnerable period for bats as their energy reserves will be at their lowest following hibernation, and food availability is therefore critical. Thus, warm springs which cause both an increase in insect food supplies but also an extended feeding season for bats since prey becomes available earlier in the season may be highly favourable to the bats (but see Andrews et al. 2016 who suggest that a delay in insect emergence may favour female pipistrelle bats in gestation/lactation). Considering the significant increase in spring temperatures in recent decades in the UK (Online Resource 8), there is strong support that climate warming has contributed to population growth.

Our results further suggest a strong negative correlation between spring precipitation and colony growth with a delay of one year, implying that the amount of precipitation will adversely influence the growth rate of the colony determined during the following year. Two plausible reasons may explain this result, namely the effect of precipitation on (i) juvenile mortality and (ii) food availability. Since spring precipitation may considerably delay the birth timing, juveniles born later in the season are less likely to accumulate enough energy reserves before hibernation. We consequently hypothesise that the rate of juvenile mortality during hibernation would be higher after wet spring conditions. Then, although the influence of precipitation on insects has been overlooked, a recent study by Esbjerg and Sigsgaard (2014) demonstrated the important impacts of rain on the phenology of the moth species Agrotis segetum: the number of precipitation days in July was strongly correlated with the mortality of 1st and 2nd instar larvae with a lag effect of one year, and soil moisture was probably the principal cause of mortality in the larvae. Given that moths 
are one of the most important food items of $R$. ferrumequinum (Jones 1990), we hypothesise that when heavy spring rainfall occurs, low prey availability during the following year would have a strong negative influence on the colony growth (but see Bontadina et al. 2008 who suggest that amount/connectivity of surrounding habitat is more important than food availability for a Rhinolophus species).

Despite the strong correlations between climatic variables and colony growth found in this study, these findings may be not extrapolated to other areas where the species occurs. Indeed, as the British population is at the northwest limit of its range, it may be more sensitive to climate change than other populations. Furthermore, we acknowledge that micro-climatic conditions caused by roost management could also have contributed to some changes in colony growth (Tuttle 1975).

\section{Density-dependence in $\boldsymbol{R}$. ferrumequinum colonies}

Our results based on the examination of a wide range of colony sizes (i.e. from 27 to more than 700 individuals) support a negative density-dependence effect. We found no evidence of an Allee effect despite the high degree of sociality in the behaviour of $R$. ferrumequinum (e.g. Rossiter et al. 2002). Since all maternity roosts monitored were in large buildings and in a few cases underground sites, competition among individuals of the same colony may not be due to roost features, but rather may arise from foraging behaviour. This fits with our findings highlighting the strong influence of available foraging habitats on colony size. Thus, individuals of larger colonies may be subject to stronger competition while foraging, and this may be amplified when few foraging areas are available. Interestingly, our results also showed that greater variation in colony growth occurs for small colonies whereas large colonies display a quasi-constant growth rate around zero, thus implying that colonies become more stable in growth rate after a certain threshold (i.e. 250 individuals). These findings emphasize that protecting smaller colonies with appropriate conservation measures may buffer against events that cause sudden decreases in colony size as larger colonies seem to be more resistant and resilient in the face of unpredicted events (Fig. 5). It is in some ways encouraging to have found no demographic Allee effect within the maternity colonies; by reducing the growth rate of populations in decline, the demographic Allee effect may lead to a rapid local extinction of a species (Courchamp et al. 2008).

\section{Implications for conservation}

This study demonstrates the value of long term, standardised monitoring of bat maternity roosts when assessing the impact of conservation management. In accordance to other studies (Duvergé and Jones 2003; Longley 2003; Dietz et al. 2013) our findings suggest that conservation actions to favour $R$. ferrumequinum populations in farmland-dominated landscapes should target the restoration and maintenance of key foraging habitats such as broadleaf woodland and grassland within the core sustenance zone of the species. Moreover, these actions must also promote the creation of a dense and connected network of green linear features (hedgerows and tree lines) for foraging and commuting purposes. Given that agricultural intensification has led to a major loss of landscape connectivity and complexity, which has been unfavourable for bat communities (Frey-Ehrenbold et al. 2013), these recommendations will also be highly beneficial for other bat species (Boughey et al. 2011b; Ashrafi et al. 2013; Heim et al. 2015). This case study based on a lightintolerant bat species also highlights another major challenge for bat conservationists: the impact of light pollution on photophobic species at a landscape scale. Previous studies have 
shown that one of the most common mitigation measures for reducing ALAN, switching street lights off after midnight, fails to mitigate its negative effect on light-intolerant bat species including $R$. ferrumequinum (Azam et al. 2015; Day et al. 2015). Therefore we recommend that remaining dark flyways within the bat's core sustenance zone should be protected and new ones created (Gaston et al. 2012).

Finally we underline the crucial need to consider the impact of climate change when evaluating conservation actions. Though we acknowledge that population trend may be a good proxy to determine the success of a conservation program, its relationship with climate should always be addressed as climate change may play a major role in driving population change (see Stephens et al. 2016).

\section{Conclusion}

Determining whether intrinsic or extrinsic factors influence changes in population sizes of a species of special conservation concern is a crucial step for (i) understanding the recovery or decline of its populations and (ii) establishing adequate conservation actions. Our results suggest that the use of a suite of population parameters is required to investigate these complex relationships. While annual colony growth rate was shown to be a good proxy to study the impact of climate, evaluating the influence of landscape features and AES required knowledge of colony sizes. These two parameters were also crucial for revealing the presence of a density-dependence effect. Finally, although landscape improvements prior to 2006 may have benefited $R$. ferrumequinum, we found no clear evidence to support the hypothesis of a potential positive effect of actual AESs implemented after 2006 on $R$. ferrumequinum populations. Rather, it seems that climate change over this period has favoured the population recovery of $R$. ferrumequinum in the UK.

Acknowledgements We are very grateful to the Bat Conservation Trust for providing data from the National Bat Monitoring Programme (NBMP). The NBMP is run by the Bat Conservation Trust, in partnership with the Joint Nature Conservation Committee, and supported and steered by Natural England, Natural Resources Wales, Northern Ireland Environment Agency, and Scottish Natural Heritage. The NBMP is indebted to all volunteers who contribute data to the programme. The greater horseshoe bat Roost Count is funded by Natural England. We thank Jennifer J. Freer for proof reading the manuscript, and S. Parsons and two anonymous reviewers who made valuable comments and suggestions that helped to improve an earlier version of the manuscript. This study was funded by the Biotechnology and Biological Sciences Research Council through the South West Biosciences Doctoral Training Partnership.

\section{Compliance with ethical standards}

Conflict of interest The authors declare that they have no conflict of interest.

Open Access This article is distributed under the terms of the Creative Commons Attribution 4.0 International License (http://creativecommons.org/licenses/by/4.0/), which permits unrestricted use, distribution, and reproduction in any medium, provided you give appropriate credit to the original author(s) and the source, provide a link to the Creative Commons license, and indicate if changes were made.

\section{References}

Andrews PT, Crump RG, Harries DJ, Andrews MM (2016) Influence of weather on a population of soprano pipistrelle bats in West Wales, UK: a 20 year study estimates population viability. Endanger Species Res 30:19-28. doi:10.3354/esr00720 
Angulo E, Roemer GW, Berec L, Gascoigne J, Courchamp F (2007) Double Allee effects and extinction in the island fox. Conserv Biol 21:1082-1091. doi:10.1111/j.1523-1739.2007.00721.x

Arnold TW (2010) Uninformative parameters and model selection using Akaike's Information Criterion. J Wildl Manag 74:1175-1178. doi:10.2193/2009-367

Ashrafi S, Rutishauser M, Ecker K, Obrist MK, Arlettaz R, Bontadina F (2013) Habitat selection of three cryptic Plecotus bat species in the European Alps reveals contrasting implications for conservation. Biodivers Conserv 22:2751-2766. doi:10.1007/s10531-013-0551-Z

Azam C, Kerbiriou C, Vernet A, Julien J-F, Bas Y, Plichard L, Maratrat J, Le Viol I (2015) Is part-night lighting an effective measure to limit the impacts of artificial lighting on bats? Glob Change Biol 21:4333-4341. doi:10.1111/gcb.13036

Azam C, Le Viol I, Julien J-F, Bas Y, Kerbiriou C (2016) Disentangling the relative effect of light pollution, impervious surfaces and intensive agriculture on bat activity with a national-scale monitoring program. Landsc Ecol. doi:10.1007/s10980-016-0417-3

Barbet-Massin M, Thuiller W, Jiguet F (2012) The fate of European breeding birds under climate, land-use and dispersal scenarios. Glob Change Biol 18:881-890. doi:10.1111/j.1365-2486.2011.02552.x

Barlow KE, Briggs PA, Haysom KA, Hutson AM, Lechiara NL, Racey PA, Walsh AL, Langton SD (2015) Citizen science reveals trends in bat populations: the National Bat Monitoring Programme in Great Britain. Biol Conserv 182:14-26. doi:10.1016/j.biocon.2014.11.022

Batáry P, Báldi A, Kleijn D, Tscharntke T (2010) Landscape-moderated biodiversity effects of agri-environmental management: a meta-analysis. Proc R Soc B 278:1894-1902. doi:10.1098/rspb.2010.1923

Bellamy C, Altringham J (2015) Predicting species distributions using record centre data: multi-scale modelling of habitat suitability for bat roosts. PLoS One 10:e0128440. doi:10.1371/journal.pone. 0128440

Boldogh S, Dobrosi D, Samu P (2007) The effects of the illumination of buildings on house-dwelling bats and its conservation consequences. Acta Chiropterol 9:527-534

Bontadina F, Schmied SF, Beck A, Arlettaz R (2008) Changes in prey abundance unlikely to explain the demography of a critically endangered Central European bat. J Appl Ecol 45:641-648. doi:10.1111/j. 1365-2664.2007.01417.x

Boughey KL, Lake IR, Haysom KA, Dolman PM (2011a) Effects of landscape-scale broadleaved woodland configuration and extent on roost location for six bat species across the UK. Biol Conserv 144:2300-2310. doi:10.1016/j.biocon.2011.06.008

Boughey KL, Lake IR, Haysom KA, Dolman PM (2011b) Improving the biodiversity benefits of hedgerows: how physical characteristics and the proximity of foraging habitat affect the use of linear features by bats. Biol Conserv 144:1790-1798. doi:10.1016/j.biocon.2011.02.017

Bowler DE, Haase P, Kröncke I, Tackenberg O, Bauer HG, Brendel C, Brooker RW, Gerisch M, Henle K, Hickler T, Hof C, Klotz S, Kühn I, Matesanz S, O’Hara R, Russell D, Schweigen O, Valladares F, Welk E, Wiemers M, Böhning-Gaese K (2015) A cross-taxon analysis of the impact of climate change on abundance trends in central Europe. Biol Conserv 187:41-50. doi:10.1016/j.biocon.2015.03.034

Brook BW, Sodhi NS, Bradshaw CJA (2008) Synergies among extinction drivers under global change. Trends Ecol Evol 23:453-460. doi:10.1016/j.tree.2008.03.011

Burnham KP, Anderson DR (2002) Model selection and multimodel inference: a practical informationtheoretic approach. Springer, New York

Burns F et al (2016) Agricultural management and climatic change are the major drivers of biodiversity change in the UK. PLoS One 11:e0151595-e0151595. doi:10.1371/journal.pone.0151595

Collins J (2016) Bat surveys for professional ecologists: good practice guidelines, 3rd edn. The Bat Conservation Trust, London

Concepción ED, Díaz M, Kleijn D, Báldi A, Batáry P, Clough Y, Gabriel D, Herzog F, Holzschuh A, Knop E, Marshall E, Tscharntke T, Verhulst J (2012) Interactive effects of landscape context constrain the effectiveness of local agri-environmental management. J Appl Ecol 49:695-705. doi:10.1111/j.13652664.2012.02131.x

Courchamp F, Clutton-Brock T, Grenfell B (1999) Inverse density dependence and the Allee effect. Trends Ecol Evol 14:405-410. doi:10.1016/s0169-5347(99)01683-3

Courchamp F, Berec L, Gascoigne J (2008) Allee effects in ecology and conservation. Environ Conserv 36:80-85. doi:10.1017/S0376892909005384

Day J, Baker J, Schofield H, Mathews F, Gaston K (2015) Part-night lighting: implications for bat conservation. Anim Conserv 18:512-516. doi:10.1111/acv.12200

de Chazal J, Rounsevell MDA (2009) Land-use and climate change within assessments of biodiversity change: a review. Global Environ Change-Human Policy Dimens 19:306-315. doi:10.1016/j. gloenvcha.2008.09.007 
Development Core Team R (2015) R: a language and environment for statistical computing. R Foundation for Statistical Computing, Vienna

Dietz M, Pir JB, Hillen J (2013) Does the survival of greater horseshoe bats and Geoffroy's bats in Western Europe depend on traditional cultural landscapes? Biodivers Conserv 22:3007-3025. doi:10.1007/ s10531-013-0567-4

Duvergé P, Jones G (1994) Greater horseshoe bats-activity, foraging behaviour and habitat use. Br Wildl 6:69

Duvergé P, Jones G (2003) Habitat use by greater horseshoe bats. In: Tattersall F, Manley W (eds) Conservation and conflict: mammals and farming in Britain. Westbury Publishing, West Yorkshire, pp 64-81

Esbjerg P, Sigsgaard L (2014) Phenology and pest status of Agrotis segetum in a changing climate. Crop Prot 62:64-71. doi:10.1016/j.cropro.2014.04.003

Faraway JJ (2006) Extending the linear model with R. Chapman and Hall, London

Flanders J, Jones G (2009) Roost use, ranging behavior, and diet of greater horseshoe bats (Rhinolophus ferrumequinum) using a transitional roost. J Mammal 90:888-896. doi:10.1644/08-MAMM-A-352.1

Foley JA et al (2005) Global consequences of land use. Science 309:570-574. doi:10.1126/science.1111772

Frey-Ehrenbold A, Bontadina F, Arlettaz R, Obrist MK (2013) Landscape connectivity, habitat structure and activity of bat guilds in farmland-dominated matrices. J Appl Ecol 50:252-261. doi:10.1111/13652664.12034

Fuentes-Montemayor E, Goulson D, Park KJ (2011) Pipistrelle bats and their prey do not benefit from four widely applied agri-environment management prescriptions. Biol Conserv 144:2233-2246. doi:10. 1016/j.biocon.2011.05.015

Gaston KJ, Davies TW, Bennie J, Hopkins J (2012) Review: reducing the ecological consequences of nighttime light pollution: options and developments. J Appl Ecol 49:1256-1266. doi:10.1111/j.1365-2664. 2012.02212.x

Gilroy JJ, Virzi T, Boulton RL, Lockwood JL (2012) Too few data and not enough time: approaches to detecting Allee effects in threatened species. Conserv Lett 5:313-322. doi:10.1111/j.1755-263X.2012. 00245.x

Gregory SD, Jones G (2010) Bats and Allee effects: when social behaviours go batty. Biologist 57:195-205

Hale JD, Fairbrass AJ, Matthews TJ, Davies G, Sadler JP (2015) The ecological impact of city lighting scenarios: exploring gap crossing thresholds for urban bats. Glob Change Biol 21:2467-2478. doi:10. $1111 /$ gcb. 12884

Heim O, Treitler JT, Tschapka M, Knörnschild M, Jung K (2015) The importance of landscape elements for bat activity and species richness in agricultural areas. PLoS ONE 10:e0134443. doi:10.1371/journal. pone. 0134443

Hutson AM, Mickleburgh SP, Racey PA (2001) Microchiropteran bats: global status survey and conservation action plan. IUCN, Gland, Cambridge

Jones G (1990) Prey selection by the greater horseshoe bat (Rhinolophus ferrumequinum): optimal foraging by echolocation? J Anim Ecol 59:587-602. doi:10.2307/4882

Jones G, Duvergé PL, Ransome RD (1995) Conservation biology of an endangered species: field studies of greater horseshoe bats. In: Racey PA, Swift SM (eds) Ecology, Evolution and Behaviour of Bats, Symposia of the Zoological Society of London, pp 309-324

Jones PD, Jonsson T, Wheeler D (1997) Extension to the North Atlantic Oscillation using early instrumental pressure observations from Gibraltar and south-west Iceland International. J Climatol 17:1433-1450. doi:10.1002/(sici)1097-0088(19971115)17:13<1433:aid-joc203>3.0.co;2-p

Jones G, Jacobs DS, Kunz TH, Willig MR, Racey PA (2009) Carpe noctem: the importance of bats as bioindicators. Endanger Species Res 8:93-115. doi:10.3354/esr00182

Limpens HJGA, Kapteyn K (1991) Bats, their behaviour and linear landscape elements. Myotis 29:39-48

Longley M (2003) Greater horseshoe bat project 1998-2003. English Nature Report No. 532. Natural England, UK

MacDonald MA, Cobbold G, Mathews F, Denny MJH, Walker LK, Grice PV, Anderson GQA (2012a) Effects of agri-environment management for cirl buntings on other biodiversity. Biodivers Conserv 21:1477-1492. doi:10.1007/s10531-012-0258-6

MacDonald MA, Morris AJ, Dodd S, Johnstone I, Beresford A, Angell R, Haysom K, Langton S, Tordoff GM, Brereton T, Hobson R, Shellswell C, Hutchinson N, Dines T, Wilberforce EM, Parry R, Matthews V (2012b). Welsh Assembly Government Contract 183/2007/08 to Undertake Agri-environment Monitoring and Services. Lot $2-$ Species Monitoring

McGarigal K, Cushman SA, Neel MC, Ene E (2002) FRAGSTATS: spatial pattern analysis program for categorical maps. University of Massachusetts, Amherst 
Mehr M, Brandl R, Hothorn T, Dziock F, Foerster B, Mueller J (2011) Land use is more important than climate for species richness and composition of bat assemblages on a regional scale. Mamm Biol 76:451-460. doi:10.1016/j.mambio.2010.09.004

Morton D, Rowland C, Wood C, Meek L, Marston C, Smith G, Wadsworth R, Simpson IC (2011) Final Report for LCM2007-the new UK land cover map. Countryside Survey Technical Report No 11/07

Pannekoek J, van Strien A (2001) TRIM 3 manual (trends \& indices for monitoring data). Statistics Netherlands

Parmesan C, Yohe G (2003) A globally coherent fingerprint of climate change impacts across natural systems. Nature 421:37-42. doi:10.1038/nature01286

Parsons S, Jones G (2000) Acoustic identification of twelve species of echolocating bat by discriminant function analysis and artificial neural networks. J Exp Biol 203:2641-2656

Pimm SL, Raven P (2000) Biodiversity—extinction by numbers. Nature 403:843-845. doi:10.1038/ 35002708

Ransome RD (2008) Greater horseshoe bat. In: Harris S, Yalden DW (eds) Mammals of the British Isles: handbook, 4th edn. The Mammal Society, Southampton, pp 298-306

Ransome RD, McOwat TP (1994) Birth timing and population changes in greater horseshoe bat colonies (Rhinolophus ferrumequinum) are synchronized by climatic temperature. Zool J Linn Soc 112:337-351. doi:10.1111/j.1096-3642.1994.tb00324.x

Razgour O, Hanmer J, Jones G (2011) Using multi-scale modelling to predict habitat suitability for species of conservation concern: the grey long-eared bat as a case study. Biol Conserv 144:2922-2930. doi:10. 1016/j.biocon.2011.08.010

Rossiter SJ, Jones G, Ransome RD, Barratt EM (2002) Relatedness structure and kin-biased foraging in the greater horseshoe bat (Rhinolophus ferrumequinum). Behav Ecol Sociobiol 51:510-518. doi:10.1007/ s00265-002-0467-1

Russo D, Cistrone L, Garonna AP, Jones G (2010) Reconsidering the importance of harvested forests for the conservation of tree dwelling bats. Biodivers Conserv 19:2501-2515. doi:10.1007/s10531-010-9856-3

Sæther BE, Ringsby TH, Roskaft E (1996) Life history variation, population processes and priorities in species conservation: towards a reunion of research paradigms. Oikos 77:217-226. doi:10.2307/ 3546060

Schaub M, Gimenez O, Sierro A, Arlettaz R (2007) Use of integrated modeling to enhance estimates of population dynamics obtained from limited data. Conserv Biol 21:945-955. doi:10.1111/j.1523-1739. 2007.00743.x

Selwood KE, McGeoch MA, Mac Nally R (2015) The effects of climate change and land-use change on demographic rates and population viability. Biol Rev 90:837-853. doi:10.1111/brv.12136

Stebbings RE (1988) Conservation of European bats. Christopher Helm Publishers, London

Stephens PA, Sutherland WJ, Freckleton RP (1999) What is the Allee effect? Oikos 87:185-190. doi:10. 2307/3547011

Stephens PA et al (2016) Consistent response of bird populations to climate change on two continents. Science 352:84-87. doi:10.1126/science.aac4858

Stone EL, Jones G, Harris S (2009) Street lighting disturbs commuting bats. Curr Biol 19:1123-1127. doi:10.1016/j.cub.2009.05.058

Threlfall CG, Law B, Banks PB (2013) The urban matrix and artificial light restricts the nightly ranging behaviour of Gould's long-eared bat (Nyctophilus gouldi). Austral Ecol 38:921-930. doi:10.1111/aec. 12034

Treitler JT, Heim O, Tschapka M, Jung K (2016) The effect of local land use and loss of forests on bats and nocturnal insects. Ecol Evol 6:4289-4297. doi:10.1002/ece3.2160

Tscharntke T, Tylianakis JM, Rand TA, Didham RK, Fahrig L, Batáry P, Bengtsson J, Clough Y, Crist TO, Dormann CF, Ewers RM, Fründ J, Holt RD, Holzschuh A, Klein AM, Kleijn D, Kremen C, Landis DA, Laurance W, Lindenmayer D, Scheber C, Sodhi N, Steffan-Dewenter I, Thies C, van der Putten WH, Westphal C (2012) Landscape moderation of biodiversity patterns and processes: eight hypotheses. Biol Rev 87:661-685. doi:10.1111/j.1469-185X.2011.00216.x

Tuttle MD (1975) Population ecology of the gray bat (Myotis grisescens): factors influencing early growth and development. Occas Pap Mus Nat Hist 36:1-24

Van der Meij T, Van Strien AJ, Haysom KA, Dekker J, Russ J, Biala K, Bihari Z, Jansen E, Langton S, Kurali A, Limpens H, Meschede A, Petersons G, Presetnik P, Prüger J, Reiter G, Rodrigues L, Schorcht W, Uhrin M, Vintulis V (2015) Return of the bats? A prototype indicator of trends in European bat populations in underground hibernacula. Mamm Biol 80:170-177. doi:10.1016/j. mambio.2014.09.004

Walsh AL, Harris S (1996) Factors determining the abundance of vespertilionid bats in Britain: geographical, land class and local habitat relationships. J Appl Ecol 33:519-529. doi:10.2307/2404981 
Walsh AL, Catto CMC, Hutson AM, Racey PA, Richardson PW, Langton SD (2001) The UK's National Bat Monitoring Programme: final report 2001. The Bat Conservation Trust, London, UK

Walther G-R, Post E, Convey P, Menzel A, Parmesan C, Beebee TJC, Fromentin J-M, Hoegh-Guldberg O, Bairlein F (2002) Ecological responses to recent climate change. Nature 416:389-395. doi:10.1038/ 416389a

Warren MS, Hill JK, Thomas JA, Asher J, Fox R, Huntley B, Roy DB, Telfer MG, Jeffcoate S, Harding P, Jeffcoate G, Willis SG, Greatorex-Davies JN, Moss D, Thomas CD (2001) Rapid responses of British butterflies to opposing forces of climate and habitat change. Nature 414:65-69. doi:10.1038/35102054

Willis CKR, Brigham RM (2007) Social thermoregulation exerts more influence than microclimate on forest roost preferences by a cavity-dwelling bat. Behav Ecol Sociobiol 62:97-108. doi:10.1007/s00265-007$0442-y$ 